\title{
On the selective deposition of tin and tin oxide on various glasses using a high power diode laser
}

\author{
J. Lawrence, P. Lubrani and L. Li \\ Laser Processing Research Centre, Department of Mechanical Engineering, University of Manchester \\ Institute of Science and Technology (UMIST), Manchester, M60 1QD, UK.
}

\section{Correspondence}

Dr. Jonathan Lawrence

Manufacturing Division,

Department of Mechanical Engineering,

University of Manchester Institute of Science and Technology (UMIST),

Manchester,

M60-1QD,

UK.

Tel : (44) $161236-3311$ ext. 3806

Fax : (44) 161 200-3803

e-mail : j.lawrence@umist.ac.uk 


\begin{abstract}
The deposition of $\mathrm{SnO}_{2}$ using a $120 \mathrm{~W}$ high power diode laser (HPDL) on both fused silica and sodalime-silica glass has been successfully demonstrated. Deposition on both glass substrates was carried out with laser power densities of $650-1600 \mathrm{~W} \mathrm{~cm}^{-2}$ and at rates of $420-1550 \mathrm{~mm} \mathrm{~min}^{-1}$. The thickness of the deposited layers was typically around $250 \mu \mathrm{m}$. The maximum theoretical coverage rate that it may be possible to achieve using the HPDL was calculated as being $3.72 \mathrm{~m}^{2} \mathrm{~h}^{-1}$. Owing to the wettability characteristics of $\mathrm{Sn}$, it proved impossible to deposit the metal on either glass substrate. Evidence of solidified microstructures was observed, with the microstructures differing considerably across the same deposited track. These differences were attributed to variations in the solidification rate, $R$, and the thermal gradient, $G$. Adhesion of the $\mathrm{SnO}_{2}$ with the soda-lime-silica glass was found to be due to mechanical bonding. The adhesion of the $\mathrm{SnO}_{2}$ with the fused silica was seen to the result of a chemical bond arising from an interface region between the $\mathrm{SnO}_{2}$ and the fused silica glass substrate. This interface region was found to be comprised of mainly Si and rich with $\mathrm{Sn}_{3} \mathrm{O}_{4}$.
\end{abstract}

Keywords: High power diode laser (HPDL); Deposition; Adhesion; Glass; Silica; Tin; Tin oxide 


\section{Introduction}

Glass is mainly used as a substrate material due to its advantages over polymers and metals, namely its high strength and generally lighter weight as compared to metallic materials. It also retains its strength to relatively higher temperatures and is less susceptible to oxidation and corrosion at these elevated temperatures. But, it is primarily the optical properties of glass which make the material interesting to use and therefore coat. Another main advantage of glass, in terms of material deposition, is its ability to cope with the stresses created by the adhering of a new atomic structure.

Thin films of optical and ferro-electric materials have acquired considerable importance in recent times in view of their impact on the emerging as well as future technologies. Films of $\mathrm{SnO}_{2}$, for example, have gained importance because of their use in opto-electronic devices, solar energy converters, light-transmitting electrodes, liquid crystals, heat mirrors, gas sensors, etc. [1]. $\mathrm{SnO}_{2}$ has traditionally been coated onto glass mainly as a base for glass-to-metal seals due to its good wetting behaviour [2]. Within the electronics industry the deposition of $\mathrm{SnO}_{2}$ on glass has found many uses, primarily nowadays being used on inorganic glasses to produce LCD displays on portable computers [3]. Thin $\mathrm{SnO}_{2}$ films are also used extensively in solar energy converters as conducting buffer layers to improve electric conductivity with low resistivity [4]. Within the aerospace industry, $\mathrm{SnO}_{2}$ is coated onto various plastic substrates. This coating can range from high resistance coatings on polyamide film or FEP film, for static dissipative uses as resistant static discharges. The coatings are also used for electromagnetic interference shielding on windows [5]. A limited amount of evidence of the application of $\mathrm{Sn}$ and $\mathrm{SnO}_{2}$ coatings in fields of gas sensing [6], biomedicine [7] and the automotive industry [8] can also be found.

At present, the coating of $\mathrm{Sn}$ and $\mathrm{SnO}_{2}$ on glass for the above applications has traditionally been achieved by means of a number of mechanical: sputtering, spin deposition and plasma spraying, [9, 10] and physical methods: ion implantation and sol-gel processing [11, 12]. In more recent times, however, the use of lasers to directly and indirectly melt and fuse metals onto many substrates, including glass, has been investigated. The laser deposition of $\mathrm{Sn}$ and $\mathrm{SnO}_{2}$ on glass derives from the need to control the interface between the two surfaces. Consequently the laser is an ideal tool for this task since it can deliver a high power beam to the interface without changing the bulk substrate dramatically [13]. Both laser chemical vapour deposition (LCVD) [14] and laser physical vapour deposition (LPVD) [15] have been shown to be viable techniques. Pulsed laser deposition (PLD) has 
been employed successfully to deposit thin films (100-1000 $\AA$ ) of indium tin oxide (ITO) onto glass substrates with a $\mathrm{KrF}$ excimer laser [16]. The laser spraying of metallic particles onto various substrates has been studied [17], but the technique is not without attendant problems as the particles require certain properties for the phenomenon of evaporation induced propulsion to be realised. The possibility of pre-placed powder deposition with $\mathrm{CO}_{2}$ and $\mathrm{Nd}$ :YAG lasers has also been investigated [17]. However, due to the lasers' characteristics, much difficulty in achieving low dilution fusion because of the small operating window was experienced.

This present work describes the hitherto unreported successful demonstration of the selective deposition of a relatively thick tin oxide layer on ubiquitous soda-lime-silica glass and fused silica glass using a HPDL in normal atmospheric conditions. The required laser operating parameters are given. Furthermore, the bonding and adhesion mechanisms involved in the process are comprehensively investigated, thus elucidating the reasons for successful deposition. It is believed that the technique presented in this paper is a useful addition to the burgeoning applications base of the HPDL.

\section{Experimental procedures}

The laser used in the study was a surgical HPDL (Diomed, Inc.), emitting at $940 \mathrm{~nm}$ and operating in the continuous wave $(\mathrm{CW})$ mode with rated optical powers ranging from 0-120 W. The HPDL beam was delivered to the work area by means of a $4 \mathrm{~m}$ long, $600 \mu \mathrm{m}$ core diameter optical fibre, the end of which was connected to a 2:1 focusing lens assembly mounted on the z-axis of a 3-axis CNC gantry table. The samples were irradiated using the defocused high order mode HPDL beam with a beam spot diameter of $2 \mathrm{~mm}$ and laser powers (measured at the workpiece using a Power Wizard power meter) of 10-55 W. The defocused HPDL beam was fired across the surfaces of the glasses selected with the $\mathrm{Sn}$ and $\mathrm{SnO}_{2}$ pre-placed beneath on a mild steel substrate as shown in Fig. 1. The HPDL beam was traversed over the surfaces of the samples using the $\mathrm{x}$ - and $\mathrm{y}$-axis of the CNC gantry table at speeds ranging from $240-1440 \mathrm{~mm} \mathrm{~min}^{-1}$. The laser optics were protected by means of a coaxially blown $\mathrm{O}_{2}$ shield gas jet a rate of $31 \mathrm{~min}^{-1}$. The glasses used as substrates for the work were fused silica glass (99.9\%fused) and the common soda-lime-silica glass. The metals deposited on the glasses were pure $\mathrm{Sn}$ and $\mathrm{SnO}_{2}\left(\mathrm{Sn} 78.77 \mathrm{wt} \%, \mathrm{O}_{2} 21.23 \mathrm{wt} \%\right)$. 


\section{Deposition of $\mathrm{SnO}_{2}$ on fused silica and soda-lime-silica glass}

\subsection{Operating window}

Fig. 2 depicts a schematic representation of the operating window for the deposition of $\mathrm{SnO}_{2}$ on both fused silica and soda-lime-silica glass. Within the optimum operating conditions (shaded area), the deposition of lines of $\mathrm{SnO}_{2}$ which adhered well to the glass were possible. Furthermore, from Fig. 2 it is possible to ascertain the maximum deposition/coverage rate that it may be possible to achieve using the HPDL. This was calculated as being $3.72 \mathrm{~m}^{2} \mathrm{~h}^{-1}$ for a circular beam of $4 \mathrm{~mm}$ diameter with a laser power of $110 \mathrm{~W}$ and a traverse speed of $1550 \mathrm{~mm} \mathrm{~min}^{-1}$.

\subsection{Morphological characteristics}

The typical surface morphology of deposited tracks of $\mathrm{SnO}_{2}$ on (a) fused silica and (b) soda-limesilica glass is shown in Fig. 3. As is evident from Fig. 3(a), the surface of the deposited $\mathrm{SnO}_{2}$ tracks on the fused silica glass appear to be slightly undulated, with the undulations being regular in both periodicity and intensity. In addition, the surface displays very few microcracks and no porosities. In contrast, Fig. 3(b) shows that the surface of the deposited $\mathrm{SnO}_{2}$ tracks on the soda-lime-silica glass are considerably more irregular and uneven. In Fig. 3(a) the solidification structure appears to be of a directional nature. This directional solidification structure was seen typically to extend in a perpendicular direction from the edges of the laser melt track, tending inwards towards the centre of the track. As one can see from Fig. 3(b), cracking of the surface of the deposited $\mathrm{SnO}_{2}$ tracks was an attendant problem. Cracks were found to occur in both the deposited $\mathrm{SnO}_{2}$ tracks and the soda-limesilica glass substrate.

\subsection{Microstructural characteristics}

The typical cross-sectional microstructure around the interface between $\mathrm{SnO}_{2}$ and (a) fused silica and (b) soda-lime-silica glass is shown in Fig. 4. Both Fig. 4(a) and Fig. 4(b) show clearly that the deposited $\mathrm{SnO}_{2}$ layer seems to be well bonded to the glass substrates. But, the methods of bonding between the $\mathrm{SnO}_{2}$ and the two substrates appear to be very different. From Fig. 4(a) is possible to clearly discern an interface region between the $\mathrm{SnO}_{2}$ and the fused silica glass substrate, while in Fig. 4(b) the $\mathrm{SnO}_{2}$ layer appears to be mechanically bonded to the soda-lime-silica substrate. 


\section{Deposition of Sn on fused silica and soda-lime-silica glass}

Regardless of the HPDL operating parameters, it proved impossible to deposit pure Sn on either a fused silica glass substrate or a common soda-lime-silica glass substrate. Indeed, HPDL interaction with the Sn when placed on the surface of the soda-lime-silica glass simply resulted in the 'balling' of the $\mathrm{Sn}$; the formation of small spheres approximately the diameter of the laser beam itself. Indeed, such observations are in accord with those of Bourell et al. [18] and Agarwala et al. [19], who noted the balling phenomena during the laser sintering of ceramic powders. Fig. 5 shows a typical surface view of the balling of Sn on soda-lime-silica glass.

\section{Discussion}

\subsection{Morphological characteristics}

As one can see from Fig. 3(b), cracking of the both the $\mathrm{SnO}_{2}$ deposited layer and the soda-lime-silica substrate were a common feature of the process. The formation of cracks can be attributed mainly to thermal stresses generated during HPDL irradiation. This is due to the fact that the thermal conductivity $\mathrm{SnO}_{2}$ is such that, during laser heating, a large thermal gradient between the melt zone and the substrate exists which results in thermal stresses. Additionally, despite the fact that the process of HPDL firing the $\mathrm{SnO}_{2}$ results from a high specific rate of energy which in turn facilitates localised melting of the $\mathrm{SnO}_{2}$, the fact that a certain amount of the heat will be conducted to sections of the deposited layer where the $\mathrm{SnO}_{2}$ is already solidified, combined with existence of a relatively cold soda-lime-silica glass substrate, means that thermal stresses will be generated. During the heating phase the stresses will be compressive and relieved by plastic deformation, thus precluding crack formation. At high temperatures $\left(T \geq T_{m}\right)$ the stresses can also relieved [20]. On the other hand, during cooling when the temperature falls below $T_{m}$, then stresses will accumulate. If the fracture strength of the glass is exceeded then cracking within the melted layer will occur. The thermal stress, $\sigma$, induced by a thermal gradient can be calculated using the Kingery equation:

$$
\sigma=\frac{E \alpha \Delta T}{1-v}
$$

where $E$ is Young's modulus, $\Delta T$ is the temperature change, $\alpha$ is the coefficient of thermal expansion and $v$ is Poisson's ratio. More succinctly, $\Delta T$ is the difference between the critical temperature 
(below which stresses can no longer be relieved) and ambient temperature. For soda-lime-silica glass this is the difference between the melting point of the metals, around $1100^{\circ} \mathrm{C}$ [20] and ambient temperature $20^{\circ} \mathrm{C}$. So, by using the following values for a typical soda-lime-silica glass: $E=6.42 \times 10^{4}$ $\mathrm{MN} \mathrm{m}{ }^{-2}, \alpha=33 \times 10^{-7} \mathrm{~K}^{-1}, \Delta T=1080^{\circ} \mathrm{C}$ and $\nu=0.176$, when the $\mathrm{Sn}$ and the $\mathrm{SnO}_{2}$ were irradiated by the HPDL beam the resulting thermal stress produced in the glass according to Equation (1) was around $277 \mathrm{MN} \mathrm{m}^{-2}$. Since this is well in excess of the fracture strength of the glass, $120 \mathrm{MN} \mathrm{m}^{-2}[20]$, cracking will occur, and can only be avoided by severe distortion or through the reduction of $\Delta T$ by pre-heating.

\subsection{Solidification microstructures}

As can be seen from Fig. 6(a), the microstructure obtained on the edges of the deposited tracks appears to be of a fine, elongated cellular nature. In contrast, the microstructures typically observed in the centre of the deposited tracks, as shown in Fig. 6(b) appear to be semi-ordered dendritic structures.

It is evident from Fig. 6 that the solidification microstructures obtained differed across the same track. Such differences in microstructure within the same track result from the fact that at the edge of the melt track the solidification rate, $R$, is low while the thermal gradient, $G$, is at its steepest, therefore $G / R$ is high along the fusion line of the melt pool. Towards the centre of the melt zone the solidification rate is increased while the thermal gradient is reduced. Consequently $G / R$ rapidly falls off as solidification proceeds towards the centre of the melt zone. Thus the high $G / R$ ratio at the interface is just slightly less than that required for stability, that is the degree of constitutional supercooling is smaller, thus different microstructures at the edges of the solidification melt tracks can be formed [21-23].

It is also worthy to note that the formation of the fine elongated structures at the edges of the solidification tracks seen in Fig. 6(a) could be due to the fact that, although the HPDL beam is not truly Gaussian in nature, the power intensity profile of the beam produces a temperature gradient perpendicular to the direction of traverse [24]. As such, the cooling rate, $\mathrm{T}$, of the $\mathrm{SnO}_{2}$ will be much faster on the edge of the laser track than in the centre, and may therefore give rise to the much finer and elongated microstructures observed on the edges of the deposited tracks.

The directionally-solidified nature of the microstructure observed on Fig. 3(a), which were seen to extend in a perpendicular direction from the edges of the laser melt track, tending inwards towards 
the centre of the track, is thought to be due to the fact that the HPDL beam intensity is at a maximum in the centre of the profile [25]. For this reason, and because the HPDL beam is circular in shape which results accordingly in the longest interaction occurring in the centre, the highest temperatures occur in the centre of the track with the lowest temperatures being experienced on the edge of the laser track. Consequently solidification begins at the edges of the track and develops quickly inwards as the laser beam is traversed away. Such observations of directional-solidification are in accord with those of Easterling [26] during welding processes and Bradley et al. [27] during $\mathrm{CO}_{2}$ laser and HPDL treatment of $\mathrm{Al}_{2} \mathrm{O}_{3}$ based refractory materials.

\subsection{The effects of wettability characteristics}

As Fig. 5 shows, it was not possible under any circumstances to deposit pure Sn on any of the glass substrates. It is asserted that this occurrence can be ascribed entirely to the wettability characteristics of the materials. This supposition is borne out somewhat by Fig 7 which shows an optical micrograph of a sessile drop of (a) $\mathrm{SnO}_{2}$ and (b) $\mathrm{Sn}$, both at $20^{\circ} \mathrm{C}$ placed on the surface of fused silica glass with the contact angle superimposed. As one can see from Fig. 7, a considerable difference in the observed contact angle between both the $\mathrm{SnO}_{2}$ and the $\mathrm{Sn}$ and the fused silica glass. Moreover, as is evident from Fig. 7(a), the contact angle formed between the Sn and the fused silica glass is in excess of $90^{\circ}$, therefore precluding the possibility of wetting and adhesion occurring [18, 19, 25].

The particular nature of the wetting characteristics of metal oxides with silicate surfaces is very well documented [10]. The adhesion between glasses and oxides is strong primarily because the two materials are ionic in structure[10]. Nonetheless, the $\mathrm{O}_{2}$ content of a material's surface is most certainly an influential factor effecting the wetting performance of the material [28, 29]. It is perhaps not surprising then that wetting of either glass could not be achieved with the pure Sn since its $\mathrm{O}_{2}$ content is naturally considerably less than that of $\mathrm{SnO}_{2}$. Moreover, it is reasonable to conclude that, whereas the $\mathrm{O}_{2}$ content of the pure $\mathrm{Sn}$ is so low that it precludes the material from wetting the selected glasses, the $\mathrm{O}_{2}$ content of the $\mathrm{SnO}_{2}$ is sufficiently high for the material to wet and bond to the glasses. Additionally, it is important to consider the relative intregrities of the glasses during HPDL deposition. As Fig. 3(b) revealed, the integrity of the soda-lime-silica glass surface could not be kept entirely because of the generated thermal gradients being beyond the glasses strength limits. Consequently cracking occurred which undermined the glass. This constraint for the use of sodalime-silica glass has being noticed before by Vispute et al. [30]. 


\subsection{Bonding characteristics}

From Fig. 4 it is clear that the bonding mechanisms between the $\mathrm{SnO}_{2}$ and the two glasses are very different. From Fig. 3(b) the $\mathrm{SnO}_{2}$ layer exhibits a microstructure characteristic of a mechanical bond. As is evident from Fig. 4(b), the mechanical bond generated between the $\mathrm{SnO}_{2}$ and the soda-limesilica glass is as one would expect insofar as the microstructures of the of the two materials appear to be interlocking. In this instance it would seem that during the bonding process, the liquid $\mathrm{SnO}_{2}$ flowed with varying degrees of ease into small cavities and asperities present on the surface of the soda-lime-silica glass. Indeed, such bonds are typical for most oxides on soda-lime-silica glass substrates $[10,30]$. In Fig. 4(a), however, the presence of an interface region between the $\mathrm{SnO}_{2}$ and the silica glass substrate is clearly visible, indicating the presence of some form of chemical bond. The results of an XRD analysis of the interface region and the deposited $\mathrm{SnO}_{2}$ layer are shown in Fig. 8. The lower plot shows the results obtained from an analysis within the $\mathrm{SnO}_{2}$ layer deposited on fused silica glass, whilst the upper plot shows the results of an analysis of the interface region generated between the deposited $\mathrm{SnO}_{2}$ layer and the fused silica glass. As one can see from the lower plot, the deposited $\mathrm{SnO}_{2}$ layer, as is to be expected, contains large amounts of $\mathrm{Sn}$ and much smaller amounts of $\mathrm{Sn}_{3} \mathrm{O}_{2}$. From the lower plot, on the other hand, it can be seen that the generated interface layer is again comprised mainly of $\mathrm{Sn}$, but is also rich in $\mathrm{Sn}_{3} \mathrm{O}_{4}$. It was therefore possible to deduce that the only difference in the interface layer from the deposited $\mathrm{SnO}_{2}$ layer was the of $\mathrm{Sn}_{3} \mathrm{O}_{4}$. It is surmised that this $\mathrm{Sn}_{3} \mathrm{O}_{4}$ is oxygen enriched $\mathrm{SnO}_{2}$ resulting from oxide transformation or oxide bridging between the $\mathrm{SnO}_{2}$ layer and the fused silica glass.

\section{Conclusions}

The deposition of $\mathrm{SnO}_{2}$ using a $120 \mathrm{~W}$ high power diode laser (HPDL) on both fused silica and sodalime-silica glass has been successfully demonstrated. Deposition on both glass substrates was carried out with laser power densities of $650-1600 \mathrm{~W} \mathrm{~cm}^{-2}$ and at rates of $420-1550 \mathrm{~mm} \mathrm{~min}^{-1}$. The maximum theoretical coverage rate that it may be possible to achieve using the HPDL was calculated as being $3.72 \mathrm{~m}^{2} \mathrm{~h}^{-1}$. In contrast, it proved impossible to deposit pure Sn on either glass substrate, with HPDL interaction resulting in the 'balling' of the Sn on the surfaces of the glass. It is asserted that this occurrence is due entirely to differences in the wetting characteristics of the materials, in particular, the differences in the $\mathrm{O}_{2}$ content of the $\mathrm{Sn}$ and the $\mathrm{SnO}_{2}$. It is believed that the $\mathrm{O}_{2}$ content of the pure 
$\mathrm{Sn}$ is so low that it precludes the material from wetting the selected glasses, whilst the $\mathrm{O}_{2}$ content of the $\mathrm{SnO}_{2}$ is sufficiently high for the material to wet and bond to the glasses.

Evidence of solidified microstructures was observed, with the microstructures differing considerably across the same deposited track. In the centre of the track the microstructure displaying a semiordered dendritic structure, whilst on the edge of the track an elongated cell structure was seen. The observed differences in microstructure within the same track can be attributed to the fact that at the edge of the melt pool the solidification rate, $R$, is low while the thermal gradient, $G$, is at its steepest, therefore $G / R$ is high along the edge of the laser melt track. Towards the centre of the melt zone the solidification rate is increased while the thermal gradient is reduced. Consequently $G / R$ rapidly falls off as solidification proceeds towards the centre of the melt zone.

The bonding mechanisms between the $\mathrm{SnO}_{2}$ and the two glasses were found to be very different. Adhesion of the $\mathrm{SnO}_{2}$ with the soda-lime-silica glass was found to be due to mechanical bonding. The adhesion of the $\mathrm{SnO}_{2}$ with the fused silica, on the hand, was seen to the result of a chemical bond arising from an interface region between the $\mathrm{SnO}_{2}$ and the fused silica glass substrate. An XRD analysis of the interface region revealed it to be comprised of mainly $\mathrm{Si}$ and rich with $\mathrm{Sn}_{3} \mathrm{O}_{4}$. 


\section{References}

1. Koinkar, V.N., Ogale, S.B., (1991), Thin Solid Films, 206259.

2. Partridge, J.H., (1949), Glass to Metal Seals, The Society of Glass Technology: Sheffield.

3. Kazmerski, L., Racine D., (1975), Thin Solid Films, 30, 19-21.

4. Wallinga, J., Ouwen, J.D., Schropp, R.E.I., Vanderweg, W.F., (1995), Mater. Sci. Forum, 173$174,1-5$.

5. Cohn, B., Private Communication, Nov.1999.

6. Papadopoulos, P., (1996), Sensors and Actuators, B34, 524-527.

7. Biswas, D.R., (1992), Proceedings of SPIE, San Diego, Ca., USA, Vol.1649, pp 66-74.

8. Boxman, R.L., Goldsmith, S., Private communication, Oct.1999.

9. Mori, N., (1985), J. Appl. Phys. 73 (3), 154-159.

10.Pulker, H.K., (1999), Coatings on Glass, Elsevier: Amsterdam.

11.Dunbar P. Birnie, I., (1983), Metal Deposition Techniques, Chapman \& Hall: New York.

12.Allen, P.L., (1982), Proceedings of the BNES Conference on Gas-Cooled Reactors, Sep. 1982, Bristol, UK., pp. 226-233.

13.Phillips, H.M., Li, Y., Bi, Z., Zhang, B., (1996), Appl. Phys. A, 63, 347-351.

14.Steen, W.M., (1997), Laser Material Processing, Springer-Verlag: London.

15.Lau, K.Y., Bar-Chaim, N., Ury, I., Harder, C., Yariv, A., (1984), IEEE J. Quantum Elec. 20 (1), 71-79.

16.Hanus, F.F., Jadin, A., Laude, L.D., (1996), Appl. Surf. Sci. 96-98 807-812.

17.Flinkfeldt, J.D., (1980), Optics and Laser Tech. 12 (3), 252-261.

18.Bourell, D.L., Marcus, H.L., Barlow, J.W., Beaman, J.J., (1992), Int. J. Powder Metall. 28 (4), 369-381.

19.Agarwala, M., Bourell, D.L., Beaman, J.J., Marcus, H.L., Barlow, J.W., (1995), Rapid Prototyping J. 1 (1), 26-36.

20.Ayers, J.D., (1980), Thin Solid Films, 73, 199-200.

21.Flemmings, M.C., Poirer, D.R., Barone, R.V., Brody, H.D., (1970), J. Iron and Steel Inst. 208, 208-214. 
22.Jones, H., (1983), Rapid Solidification of Metals and Alloys, Institute of Metallurgists: London.

23.Mehrabian, R., (1982),Int. Metals Reviews, 27 (4), 185-209.

24.Mazumder, J., Steen, W.M., (1980), J. Appl. Phys. 51 (2), 941-947.

25.Lawrence, J., (1999), PhD Thesis, UMIST.

26.Easterling, K.E., (1992), Introduction to the Physical Metallurgy of Welding, ButterworthHeinemann: Oxford.

27.Bradley, L., Li, L., Stott, F.H., (1998), Appl. Surf. Sci. 138-139, 522-528.

28.Ueki, M., Naka, M., Okamoto, I., (1986), J. Mat. Sci. Lett. 5, 1261-1262.

29.Li, J.G., (1993), Rare Metals, 12, 84-96.

30.Vispute, R.D., Godbole, V.P., Chaudari, S.M., Kanetkar, S.M., Ogale, S.B., (1988), J. Mater. Res. 3 (6), 1180-1186. 


\section{List of Figs.}

Fig. 1. Experimental arrangement for the deposition of $\mathrm{Sn}$ and $\mathrm{SnO}_{2}$ on the selected glasses.

Fig. 2. Schematic representation of the operating window for the deposition of $\mathrm{SnO}_{2}$ on fused silica and soda-lime-silica glass using the $120 \mathrm{~W}$ HPDL.

Fig. 3. Typical optical surface morphology of $\mathrm{SnO}_{2}$ deposited on (a)fused silica and (b) soda-limesilica glass.

Fig. 4. Typical SEM cross-sectional images of $\mathrm{SnO}_{2}$ deposited on (a) fused silica and (b) soda-limesilica glass.

Fig. 5. Typical optical surface view of the phenomena of 'balling' during the deposition of Sn on soda-lime-silica glass.

Fig. 6. Typical optical surface images of the solidified microstructure of $\mathrm{SnO}_{2}$ deposited on (a) fused silica and (b) soda-lime-silica glass.

Fig. 7. Contact angles for (a) $\mathrm{SnO}_{2}$ and (b) Sn on the surface of fused silica glass.

Fig. 8. XRD analysis of the deposited $\mathrm{SnO}_{2}$ layer on fused silica glass (lower plot) and the interface region between the $\mathrm{SnO}_{2}$ and fused silica glass (upper plot). 
Fig. 1

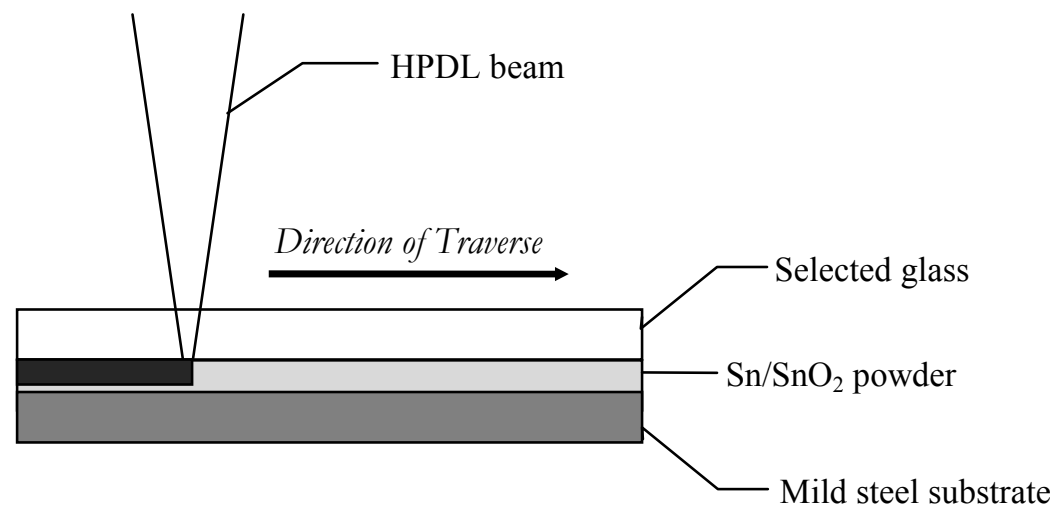


Fig. 2

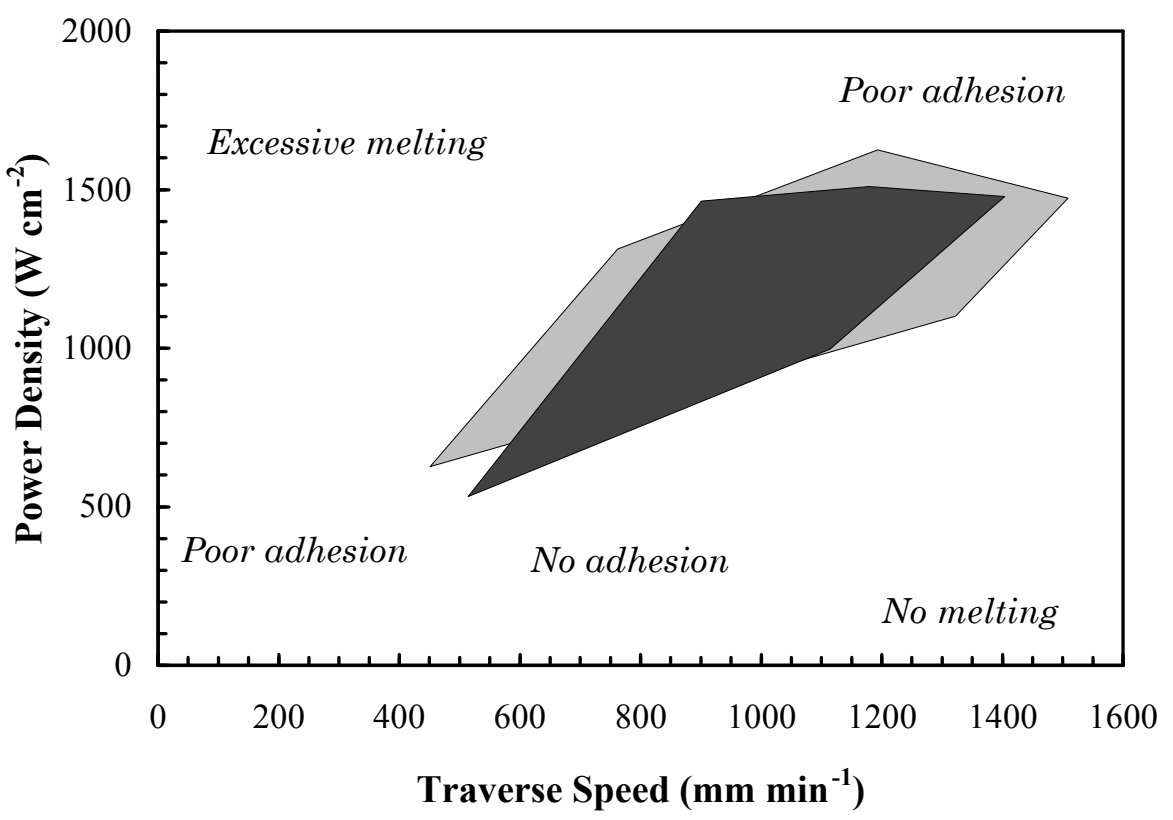

Fused Silica Glass $\bigcirc$ Soda-Lime-Silica Glass 
Fig. 3

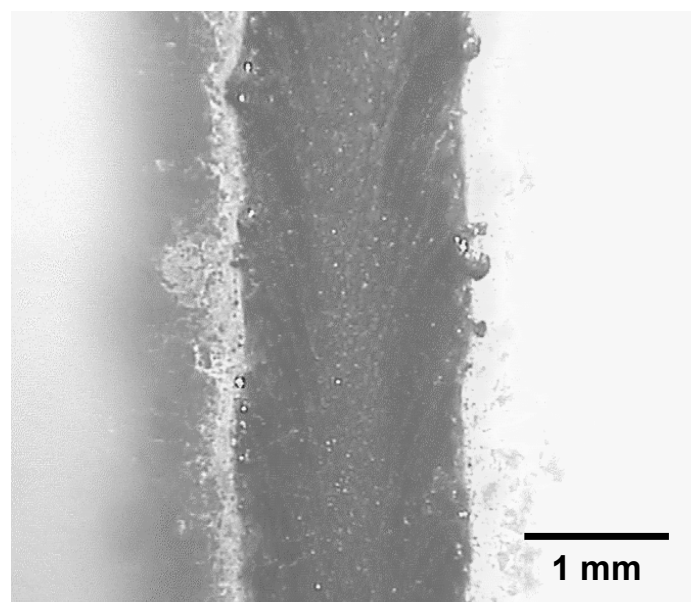

(a)

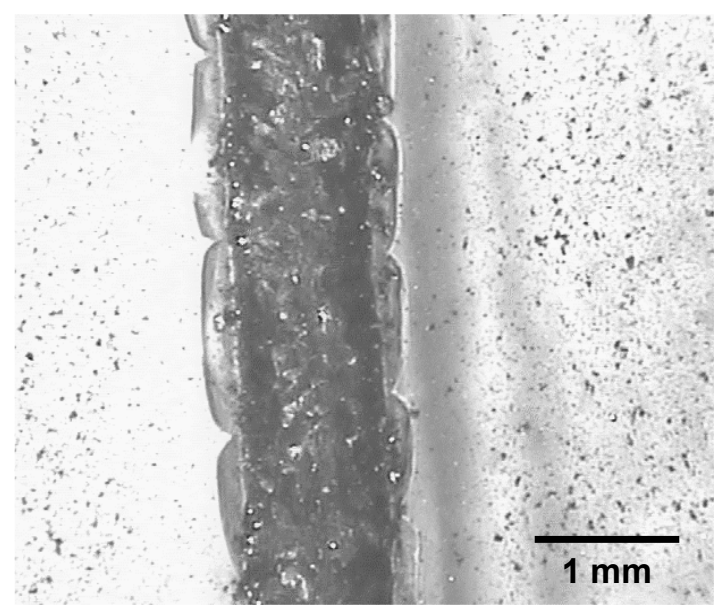

(b) 
Fig. 4

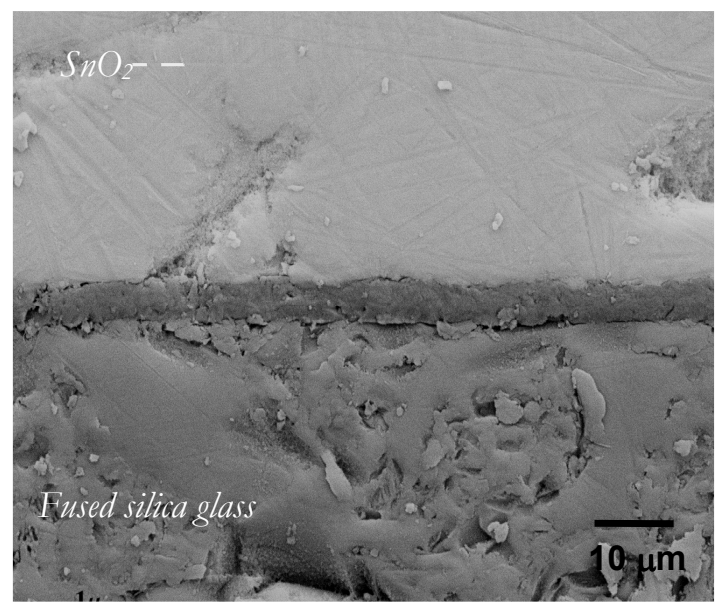

(a)

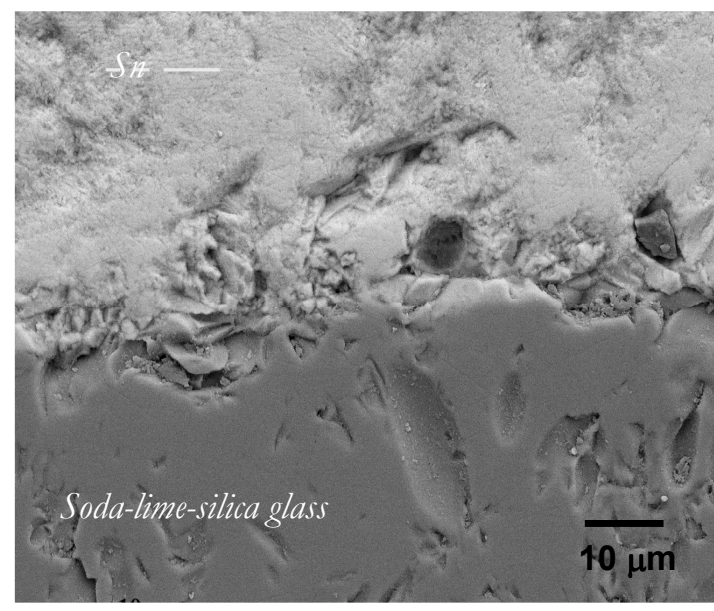

(b) 
Fig. 5

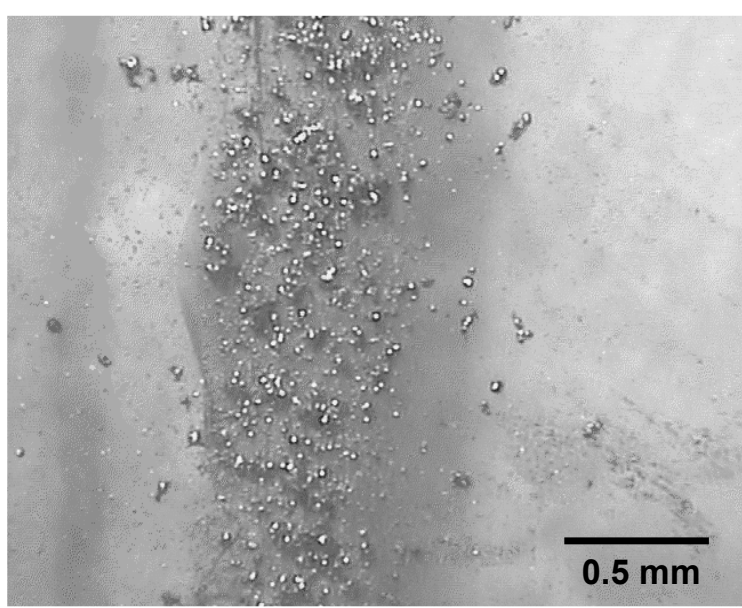


Fig. 6
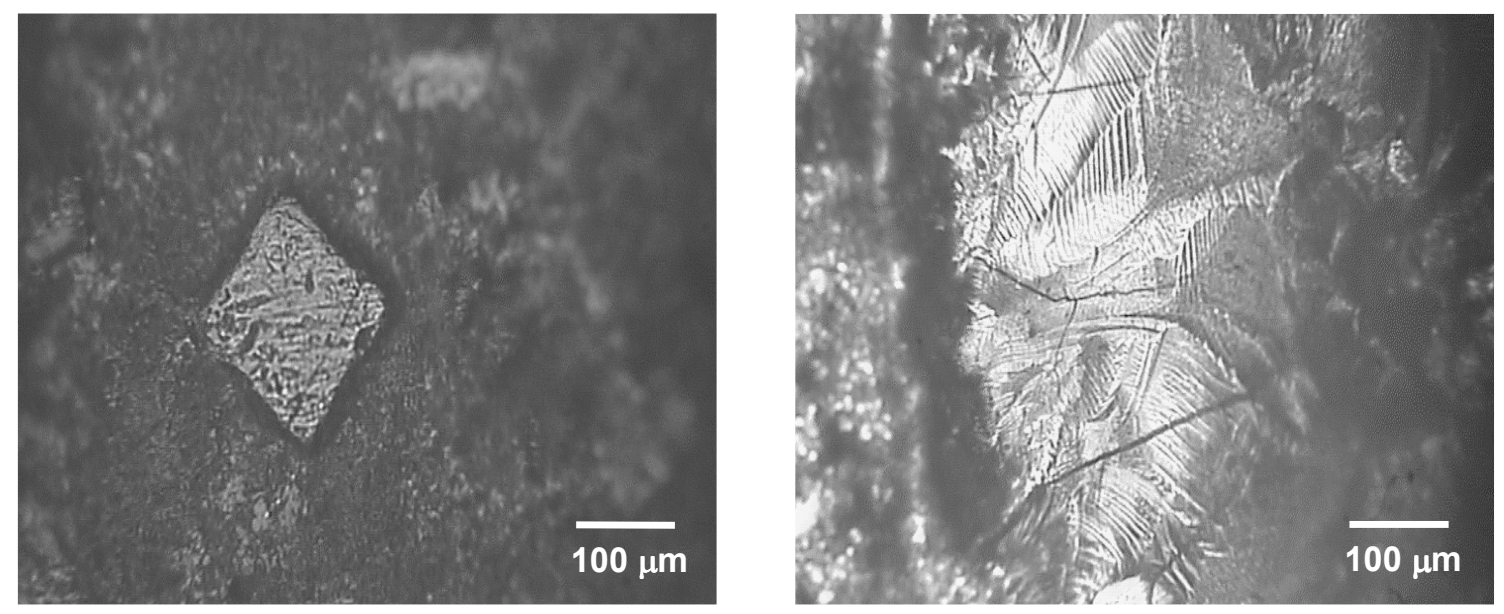

(a)

(b) 
Fig. 7
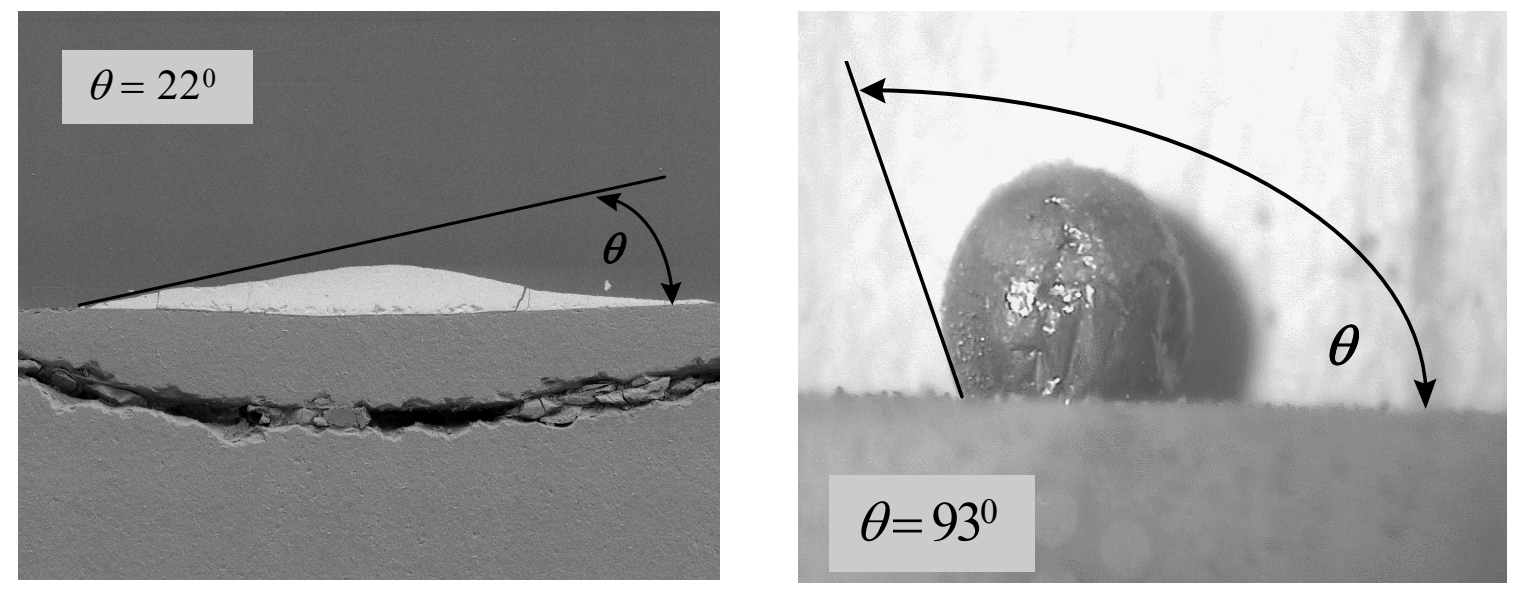

(a)

(b) 
Fig. 8

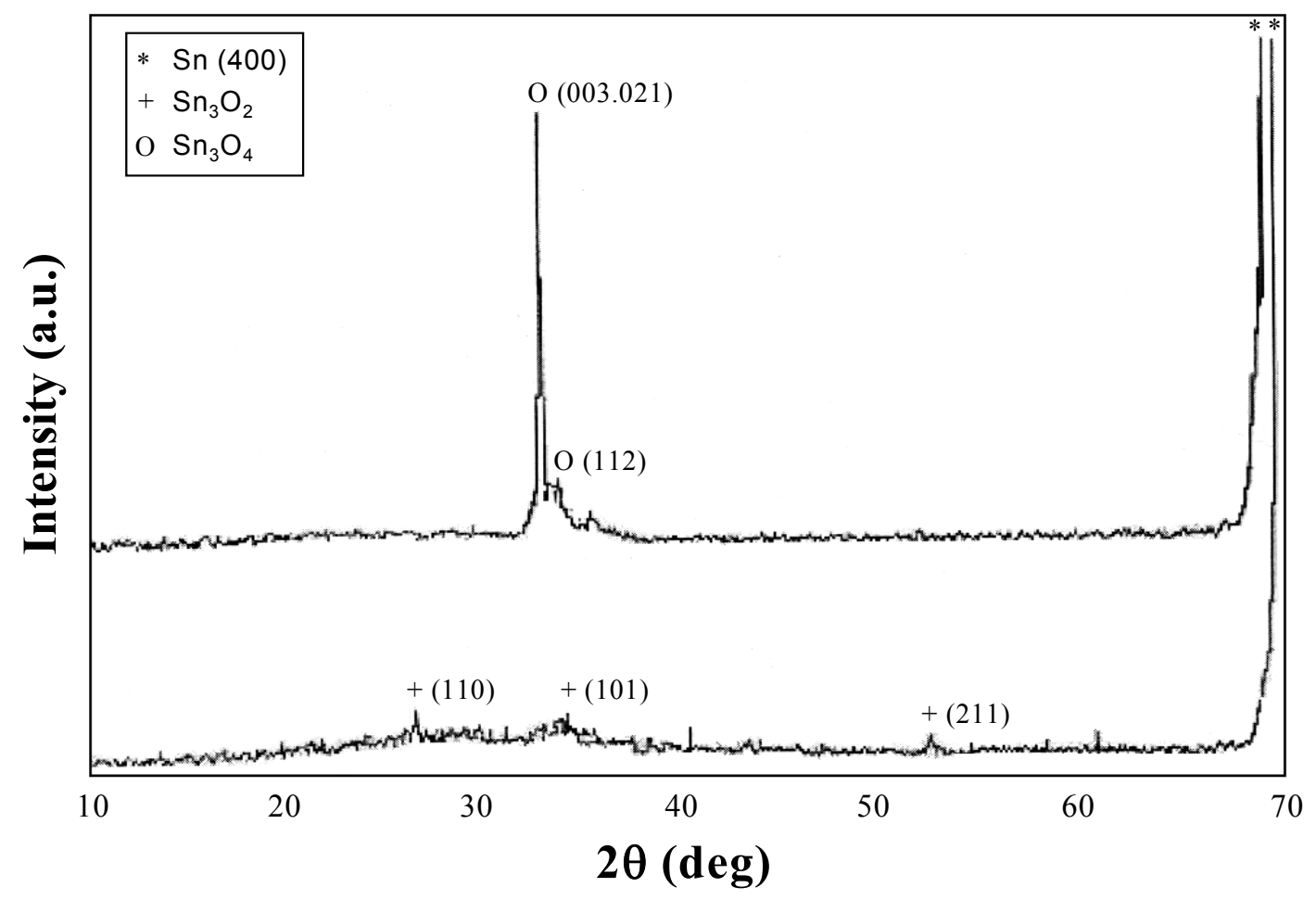

